\title{
Medication Adherence Mediates the Relationship between Marital Status and Cardiac Event-Free Survival in Patients with Heart Failure
}

\author{
Jia-Rong Wu, PhD, RN [Assistant Professor], \\ University of North Carolina at Chapel Hill, School of Nursing
}

Terry A. Lennie, PhD, RN [Associate Professor and Director of the PhD Program], University of Kentucky, College of Nursing

Misook L. Chung, PhD, RN [Associate Professor],

University of Kentucky, College of Nursing

Susan K. Frazier, PhD, RN [Associate Professor],

University of Kentucky, College of Nursing

Rebecca L. Dekker, PhD, APRN [Assistant Professor],

University of Kentucky, College of Nursing

Martha J. Biddle, PhD, RN, and

University of Kentucky, College of Nursing

Debra K. Moser, DNSc, RN, FAAN [Professor and Gill Endowed Chair of Nursing] University of Kentucky, College of Nursing

\section{Abstract}

Background-Prognosis is worse in unmarried patients compared to married patients with heart failure (HF). The reasons for differences in outcomes are unclear, but variations in medication adherence may play a role, as medication adherence is essential to achieving better outcomes.

Objective-To determine whether medication adherence mediated the relationship between marital status and cardiac event-free survival in patients with HF.

\begin{abstract}
Method-Demographic, clinical and psychosocial data were collected by questionnaires and medical record review for $136 \mathrm{HF}$ patients $(61 \pm 11,70 \%$ male, $60 \%$ NYHA III/IV). Medication adherence was monitored objectively for 3 months using the Medication Event Monitoring System. Cardiac event-free survival data were obtained by patient/family interview, hospital data base and death certificate review. A series of regression and Cox-survival analyses were performed to determine whether medication adherence mediated the relationship between marital status and event-free survival.
\end{abstract}

Results-Cardiac event-free survival was worse in unmarried patients than married patients. Unmarried patients were more likely to be nonadherent and were 2 times more likely to

\footnotetext{
(C) 2011 Mosby, Inc. All rights reserved.

Address for correspondence: Jia-Rong Wu, PhD, RN University of North Carolina at Chapel Hill, School of Nursing 435 Carrington Hall, CB \# 7460 Chapel Hill, NC 27599-7460 Phone 919-966-8057 Fax 919-843-9900 jiarongw@ email.unc.edu.

Publisher's Disclaimer: This is a PDF file of an unedited manuscript that has been accepted for publication. As a service to our customers we are providing this early version of the manuscript. The manuscript will undergo copyediting, typesetting, and review of the resulting proof before it is published in its final citable form. Please note that during the production process errors may be discovered which could affect the content, and all legal disclaimers that apply to the journal pertain.
} 
experience an event than married patients $(p=.017)$. Marital status was not a significant predictor of event-free survival after entering medication adherence in the model, demonstrating a mediation effect of adherence on the relationship of marital status to survival.

Conclusion-Medication adherence mediated the relationship between marital status and eventfree survival. It is important to design interventions to increase medication adherence that take into account subgroups, such as unmarried patients, who are at higher risk for nonadherence.

\section{Keywords}

medication adherence; heart failure; outcomes; marital status; mediator

\section{Introduction}

Heart failure (HF) is a serious chronic condition that afflicts over 5.8 million people in the United States (US). ${ }^{1}$ About 670,000 new cases are diagnosed each year for people who are 45 years of age and older. ${ }^{1}$ The HF incidence approaches $1 \%$ for those who are 65 years and older. ${ }^{1}$ Therefore, due to an aging population and increased survival from cardiovascular diseases, the number of patients with HF is expected to increase.

Medication adherence is crucial to achieve optimal HF outcomes. ${ }^{2-7}$ Patients with HF are prone to exacerbations unless they consistently adhere to their medical regimen. Most patients with HF are older with physical limitations. These patients often require assistance to adhere to prescribed medication (e.g., transportation to physician's office to keep the prescription updated, transportation and money to refill the prescription, reminders to take prescribed medications, and support to overcome cognitive changes and fatigue that could affect their ability to take medications as prescribed). ${ }^{8-12}$ Without a spouse or partner, patients with HF often have difficulty securing assistance for these needs. ${ }^{13}$

Rehospitalization and mortality rates are higher in unmarried patients with HF compared to married patients. ${ }^{14,15}$ Chin and Goldman ${ }^{15}$ followed 257 patients with $\mathrm{HF}$ and found that single patients had significantly higher rates of readmission and death than married patients. In a prospective study, other investigators identified marital quality as a predictor of survival. ${ }^{14}$ The reasons for the difference in outcomes between married and unmarried patients are unclear. Prior researchers have suggested that unmarried patients with HF have lower adherence rates than married patients with HF. ${ }^{16-19}$ Likewise, we have already reported that medication adherence ${ }^{20}$ and marital status ${ }^{21}$ independently predicted event-free survival in patients with HF. However, we do not know whether differences in medication adherence play a role in differences in outcomes between married and unmarried patients. Accordingly, the purpose of this study was to determine whether medication adherence mediates the relationship between marital status and cardiac event-free survival in patients with HF. A mediator is a variable that helps to explain how or why the independent variable predicts the outcome variable and enables investigators to explore the mechanism behind the relationship between the independent variable and the outcome variables. ${ }^{22,}{ }^{23}$ Moreover, married patients tend to report more social support ${ }^{24,25}$ and patients with more social support have better medication adherence. ${ }^{26,27}$ Investigators have postulated that it is not marital status alone, but the interaction of marital status and social support that is related to medication adherence. ${ }^{17,18,28}$ ENREF 44 Therefore, the relationships among marital status, social support and medication adherence were also examined. 


\section{Methods}

\section{Study Design}

This was secondary data analysis from a prospective, longitudinal study $8,20,29,30$ in which we examined whether the relationship between marital status and event-free survival was explained by medication adherence in patients with HF.

\section{Samples and Setting}

Detailed eligibility criteria and recruitment methods have been published previously. 8, 20, 29, 30 ENREF 21 In short, patients were recruited from outpatient cardiology clinics and inpatient cardiology wards in one Southern state. Patients with a confirmed diagnosis of chronic HF who were on stable doses of HF medications were enrolled in the study. Patients could have HF from either preserved or non-preserved systolic function. Patients were excluded if they had obvious cognitive impairment (i.e., can't give informed consent or participate in an interview), or if they had a co-existing terminal illness expected to affect study outcomes.

\section{Variables and Measures}

Marital status-Marital status was the independent variable in this study. Patient selfreported marital status was collected by patient interview. Patients who were never married, divorced, or widowed were categorized as unmarried. Those who were married or cohabitated with a significant other were categorized as married.

Medication adherence-Medication adherence was assessed daily for 3 months using a microelectronic medication monitoring device (Medication Event Monitoring System [MEMS], AARDEX®-USA, Union City, CA). The MEMS registered each date and time the cap was removed. Medication adherence from the MEMS was defined as the percentage of days the correct number of doses were taken during the 3-month monitoring period. ${ }^{31}$ Patients who took the correct number of doses on at least $88 \%$ of days were categorized as adherent, while all others were categorized as non-adherent. This cutpoint was chosen based on research demonstrating that adherence at or above this level predicted better event-free survival. ${ }^{30}$

Each patient was asked to put one HF prescription medication in the MEMS bottle. Priority was given to medications taken twice a day. The beta-adrenergic antagonist agent was chosen primarily as the drug to monitor, unless the patient was not prescribed one. In those cases, the angiotensin-converting-enzyme (ACE) inhibitor or angiotensin receptor blocker (ARB) was used. If the participant was not prescribed a beta-antagonist, or ACE inhibitor or ARB, a diuretic or digoxin was monitored in the MEMS bottle. Prior researchers have demonstrated that use of the MEMS to monitor only one medication is sufficient to reflect medication taking behavior related to total patient medication regimens, ${ }^{32-34}$ that opening of the bottle does reflect actual medication taking, ${ }^{32,35}$ and that use of the MEMS does not inflate adherence artificially. ${ }^{36}$ Each patient was given a MEMS diary to record unscheduled cap openings (e.g., refilled the bottle without taking a dose, opened by accident). These unscheduled openings were excluded when data were downloaded.

Cardiac event-free survival-The outcome variable was the composite end-point of time to the first occurrence of one of the following events: cardiac ED visits, cardiac hospitalizations and cardiac mortality (i.e., cardiac event-free survival). Data about cardiac event-free survival were obtained by patient/family interview, hospital data base review and review of death certificates and records. During data collection, the date and reasons for ED visits, hospitalization and death were noted. If there was a difference between patient/family 
report and the hospital records, we carefully reviewed the medical record to confirm the visit date and reason, and discussed the discrepancy with the patient or family.

Demographic variables-Age, gender, and education level were collected as demographic variables. Patient age, gender, and education level were collected from patient interview.

Clinical variables_-Left ventricular ejection fraction (LVEF), New York Heart Association (NYHA) functional class, body mass index (BMI), and medication-taking behaviors were collected as clinical variables. LVEF was collected from the medical record review. NYHA class was determined by standardized patient interview. ${ }^{37}$ Body mass index was calculated as weight $(\mathrm{kg}) /$ height $\left(\mathrm{m}^{2}\right)$. Medication-taking behaviors were measured by the Medication Adherence Scale developed by our research team and validated in patients with HF. ${ }^{38}$

Psychological variables-Perceived social support, anxiety, and depressive symptoms were collected as psychological variables. Perceived social support was assessed using the Multidimensional Perceived Social Support Scale (MPSSS). The MPSSS is a reliable and valid instrument. ${ }^{39,40}$ Internal consistency reliability of the MPSSS for this study was demonstrated by a Cronbach's alpha of .95 . Anxiety was measured by the Anxiety Subscale of the Brief Symptom Inventory (BSI). Depressive symptoms were assessed using the Patient Health Questionnaire (PHQ). The BSI Anxiety subscale ${ }^{41}$ and PHQ- $9{ }^{42,} 43$ have established reliability and validity.

\section{Procedure}

The study received approval from the appropriate Institutional Review Boards and all patients provided written, informed consent. Patient demographic, clinical, and psychological data were collected at baseline and medication adherence monitoring with the MEMS was initiated and continued for 3 months. Outcome data for hospitalizations and cardiac event-survival were assessed up to 3.5 years by telephone interview and by reviewing patient medical records.

\section{Data Management and Analysis}

All data analyses were performed using SPSS (Chicago, IL), version 17.0; a significance level of .05 was chosen a priori. Data analysis began with a descriptive examination of all variables, including frequency distributions, means, standard deviations, medians, and interquartile ranges, as appropriate to the level of measurement of the variables.

Patients were divided into adherent and nonadherent groups based on their medication adherence rate measured by the MEMS using a cutpoint of $88 \%^{30}$ and into married or unmarried groups. Logistic regressions and t-tests were used to examine the relationships among marital status, social support and medication adherence. The log-rank test was used to compare the time to event-free survival between patients in married and un-married groups. Kaplan-Meier plots were used to graphically depict group differences in event-free survival. Cox proportional hazards regression modeling was used to assess the time to eventfree survival between these two groups with and without controlling for the following potential covariates: age, gender, education level, LVEF, NYHA class, perceived social support, anxiety, and depressive symptoms.

To test whether medication adherence was a mediator of the relationship between marital status and event-free survival, a series of regression models and Cox-survival analyses were conducted. The test for mediation followed the steps outlined by Baron et al. ${ }^{22,23,44,45}$ 
Four regression models were performed to test for the mediator effect. The first model tested whether marital status (the independent variable) was a predictor of medication adherence (mediator). The second model tested whether medication adherence was a predictor of event-free survival (outcome variable). The third model tested whether marital status was a predictor of event-free survival. In the fourth model, both marital status and medication adherence (independent and mediator variables) were entered simultaneously as predictors of event-free survival (outcome variable). The following conditions had to be met for a mediator effect to be present: 1) the first, second, and the third models were significant, and 2) the $p$ value of the coefficient associated with the independent variable (marital status) in the fourth model was higher (partial mediator) or was non-significant (full mediator) compared to the $\mathrm{p}$ value in the third model. ${ }^{22,23,46}$

\section{Results \\ Patient Characteristics}

A total of 136 patients with HF and complete MEMS data were included in the analysis. The mean age of patients in the sample was $61 \pm 11$ years and about two thirds of patients had advanced HF (NYHA class III or IV) with an average LVEF of $35 \pm 14 \%$. The majority of the patients were male (70\%) and Caucasian (90\%). One quarter of the patients did not complete high school.

A majority of participants were married (62\%). Significantly more male patients were married $(78.6 \%)$ than female patients $(21.4 \%)(p=.007)$. There were no group differences based on support from government insurance (i.e., Medicare or Medicaid), financial status, BMI, or co-morbidities (i.e., diabetes, hypertension, previous myocardial infarction and stroke). Full sample characteristics and comparisons of married vs. unmarried groups are presented in Table 1.

\section{Marital status, perceived social support, and medication adherence}

Of the total sample, 56\% were classified as adherent. Sixty-three percent of married patients were classified as adherent, while only $44 \%$ of unmarried patients were classified adherent $(p=.035)$. Compared to married patients, those who were unmarried were 2.2 times more likely to be nonadherent to their prescribed medication $(p=.033)$. Married patients perceived more social support compared to unmarried patients (70.8 vs. 58.8, $p=.001$ ); likewise, adherent patients had higher perceived social support scores than nonadherent patients $(69.1$ vs. $62.8, p=.049)$. More married patients reported having someone usually remind them to take their prescribed medications compared to unmarried patients $(p=.036)$. Also, more married patients reported having someone to help them take their prescribed medications than unmarried patients $(p<.001)$.

\section{Marital status, medication adherence and event-free survival}

There was $1 \mathrm{HF}$ death $(.7 \%), 31$ (22.8\%) cardiac-related hospital admissions, and 6 (4.4\%) $\mathrm{ED}$ visits due to cardiac reason. There was no difference in cardiac mortality rates between unmarried and married patients ( $2 \%$ vs. $0 \%, p=.959)$. The rate of cardiac hospitalizations was higher in unmarried patients than married patients ( $31 \%$ vs. $18 \%, p=.035$ ). In KaplanMeier analysis, the composite endpoint of cardiac event-free survival was significantly shorter in unmarried patients than in married patients (706 days vs 873 days, $p=.034$, Figure 1).

In a series of regression models and Cox-survival analyses, medication adherence mediated the relationship between marital status and event-free survival based on the following sequence of regression analyses. First, in Path A (Figure 2), marital status independently 
predicted medication adherence $(p=.033)$. Second, in Path B, patients who were nonadherent had 3.1 times greater risk of a cardiac event than adherent patients $(p<.001)$. Third, in Path C, marital status was an independent predictor of cardiac event-free survival. Patients who were unmarried had 2 times the risk of experiencing a cardiac event than patients who were married, before and after adjusting for age, gender, education level, LVEF, NYHA class, BMI, perceived social support, anxiety, and depressive symptoms (Table 2). In the final Path D, marital status was no longer a significant predictor of eventfree survival when medication adherence was entered into the model $(p=.08)$, indicating medication adherence is why married patients have better event-free survival. Married patients were more likely to be adherent to their prescribed medication and therefore had a longer cardiac event-free survival.

We also conduct the analyses with medication adherence as a continuous variable. In Path $\mathrm{A}$, marital status independently predicted medication adherence $(p=.004)$. In Path B, medication adherence predicted cardiac event-free survival $(p=.011)$. In the Path $\mathrm{C}$, marital status predicted cardiac event-free survival $(p=.017)$. In the final Path $\mathrm{D}$, marital status was no longer a significant predictor of event-free survival when medication adherence was entered into the model $(p=.139)$. These analyses indicated that medication adherence truly was a mediator between marital status and cardiac event-free survival when analyzed as either a dichotomized or continuous variable.

\section{Discussion}

This is the first study to examine mediation between marital status and outcomes in patients with HF. Unmarried patients with HF had a higher risk of cardiac events ${ }^{21}$ than married patients. Nonadherent patients had greater risk for having an event compared to adherent patients. ${ }^{20,30}$ Our study extends these findings by demonstrating that that medication adherence mediates the relationship between marital status and outcomes in patients with HF.

Our results are consistent with other studies in which the rates of cardiac events were higher in unmarried patients compare to married patients with $\mathrm{HF},{ }^{14,15,21}$ and those with myocardial infarction. ${ }^{13}$ Chin and Goldman found that HF patients who were single were more likely to be readmitted to the hospital or die $(\mathrm{HR}=2.1,95 \% \mathrm{CI}=1.3$ to 3.3$) .{ }^{15}$ Coyne et al. ${ }^{14}$ followed 189 patients with HF for four years and reported that marital status was a predictor of event-free survival in patients with $\mathrm{HF}(\mathrm{HR}=2.72) .{ }^{21}$ Marital quality was also a predictor of survival in these patients. In a prospective study of 1,401 patients with myocardial infarction, ${ }^{13}$ unmarried patients had a significantly higher mortality rate than married patients, both in-hospital and after discharge.

Investigators have suggested that better outcomes of married patients might be associated with greater patient adherence to medical therapy and lifestyle recommendations. ${ }^{14,}{ }^{47}$ The major finding of our study was that married patients were more likely to be adherent to prescribed medications, which was also the strongest predictor of better outcomes. Prior studies of the relationship between marital status and medication adherence have produced inconsistent results. ${ }^{17-19,26,48-50}$ While no prior investigator examined the relationship between marital status and medication adherence in HF, seven research studies have been published in patients with other chronic conditions. ${ }^{17-19,26,48-50}$ In four of the seven studies, the investigators reported no differences in medication adherence based on marital status. ${ }^{26,48-50}$ However, in a study of 1,326 patients with coronary artery disease, unmarried patients were more likely to discontinue taking medications against their doctor's advice. ${ }^{17}$ Likewise, in two other studies, unmarried participants were less adherent to prescribed medication than married participants. ${ }^{18,19}$ It is unclear why married patients are more likely 
to be adherent than unmarried patients. Investigators have suggested one reason may be that spouses facilitate adherence by providing practical support. ${ }^{17}, 18$ Rich et al. suggested that the presence of a spouse or other caregiver may increase adherence through direct supervision of medication administration. ${ }^{28}$ It appears that without the help of their family members, patients have difficulty adhering to their medication regimen, keeping their physician appointments, and following their medical plan. ${ }^{9}, 10,16,51$ In our study, compared to unmarried patients, married patients more often reported having someone usually remind them about taking their prescribed medications. They also more often reported having someone help them take their medication. Married patients perceived more social support and received more reminders and help from their spouses or partners than unmarried patients. Under these circumstances, it may not be surprising that married patients have better medication adherence compared to unmarried patients with HF.

In our study, medication adherence emerged as a mediator between marital status and poorer outcomes. When we compared sociodemographic and clinical variables between married and unmarried participants, gender, perceived social support and medication adherence were different between these two groups. Although the unmarried group had more female participants than the married group, gender was not related to event-free survival. This result is consistent with prior studies showing no gender difference in rehospitalization or mortality in HF. ${ }^{52,53}$

\section{Limitations}

There are a few limitations that might compromise the generalizability of the findings. First, we did not measure quality of the marital relationship. A poor quality marital relationship might cause more stress in daily life and exacerbate HF. ${ }^{14}$ ENREF 15 Further research is needed to examine quality of marriage, medication adherence and outcomes in patients with HF. It is also possible that married patients more closely followed a low salt diet or engaged in more physical activity compared to unmarried patients. However, these factors were not measured in this study. Inclusion of other potential factors related to marital status and medication adherence in future studies will provide further insight into the relationships among marital status, medication adherence and outcomes.

There were more male patients who were married in our study than female married patients. Although this may limit our ability to generalize the results to married females, we did adjust for gender in the multiple Cox regression. Finally, patients with HF need to take their prescribed medications for the remainder of their lives. It is possible that our 3 month monitoring period did not reflect long-term medication adherence. However, we feel that a 3-month period could also be an advantage. We were able to observe a medication-taking behavior pattern that affected cardiac event-free survival without placing too much burden on the research participants. Further longer-term measurement of medication adherence using the MEMS would be useful to confirm the findings from this study.

\section{Conclusion}

The major finding of this study was that medication adherence was a mediator of the relationship between marital status and cardiac event-free survival in this sample. Thus, determining patient marital status can help to identify those who are at higher risk of worse medication adherence and poorer outcomes. It is important to design interventions to improve medication adherence and outcomes that take into account subgroups, such as unmarried patients, who are at higher risk for nonadherence and poorer outcomes. 


\section{Acknowledgments}

This study was supported by funding from the Philips Medical-American Association of Critical Care Nurses Outcomes Grant, American Heart Association Great River Affiliate Post-doctoral Fellowship to Jia-Rong Wu, University of Kentucky General Clinical Research Center (M01RR02602), grant \# R01 NR008567 from the National Institute of Nursing Research and a Center grant to the University of Kentucky, College of Nursing from NIH, NINR, 1P20NR010679. The content is solely the responsibility of the authors and does not necessarily represent the official views of the National Institute of Nursing Research or the National Institutes of Health.

\section{References}

1. Lloyd-Jones D, Adams RJ, Brown TM, Carnethon M, Dai S, De Simone G, et al. Heart disease and stroke statistics--2010 update: A report from the american heart association. Circulation. 2010; 121:e46-e215. [PubMed: 20019324]

2. Chin MH, Goldman L. Factors contributing to the hospitalization of patients with congestive heart failure. Am. J. Public Health. 1997; 87:643-648. [PubMed: 9146445]

3. Chui MA, Deer M, Bennett SJ, Tu W, Oury S, Brater DC, et al. Association between adherence to diuretic therapy and health care utilization in patients with heart failure. Pharmacotherapy. 2003; 23:326-332. [PubMed: 12627931]

4. Happ MB, Naylor MD, Roe-Prior P. Factors contributing to rehospitalization of elderly patients with heart failure. J. Cardiovasc. Nurs. 1997; 11:75-84. [PubMed: 9200021]

5. Joshi PP, Mohanan CJ, Sengupta SP, Salkar RG. Factors precipitating congestive heart failure--role of patient non-compliance. J. Assoc. Physicians India. 1999; 47:294-295. [PubMed: 10999123]

6. Li H, Morrow-Howell N, Proctor EK. Post-acute home care and hospital readmission of elderly patients with congestive heart failure. Health Soc. Work. 2004; 29:275-285. [PubMed: 15575455]

7. Miura T, Kojima R, Mizutani M, Shiga Y, Takatsu F, Suzuki Y. Effect of digoxin noncompliance on hospitalization and mortality in patients with heart failure in long-term therapy: A prospective cohort study. Eur. J. Clin. Pharmacol. 2001; 57:77-83. [PubMed: 11372597]

8. Wu JR, Moser DK, Chung ML, Lennie TA. Predictors of medication adherence using a multidimensional adherence model in patients with heart failure. J. Card. Fail. 2008; 14:603-614. [PubMed: 18722327]

9. Riegel B, Moser DK, Anker SD, Appel LJ, Dunbar SB, Grady KL, et al. State of the science: Promoting self-care in persons with heart failure: A scientific statement from the american heart association. Circulation. 2009; 120:1141-1163. [PubMed: 19720935]

10. Wu JR, Moser DK, Lennie TA, Peden AR, Chen YC, Heo S. Factors influencing medication adherence in patients with heart failure. Heart Lung. 2008; 37:8-16. [PubMed: 18206522]

11. Thornhill K, Lyons AC, Nouwen A, Lip GY. Experiences of living with congestive heart failure: A qualitative study. Br J Health Psychol. 2008; 13:155-175. [PubMed: 18230240]

12. Riegel B, Carlson B. Facilitators and barriers to heart failure self-care. Patient Educ. Couns. 2002; 46:287-295. [PubMed: 11932128]

13. Chandra V, Szklo M, Goldberg R, Tonascia J. The impact of marital status on survival after an acute myocardial infarction: A population-based study. Am. J. Epidemiol. 1983; 117:320-325. [PubMed: 6829559]

14. Coyne JC, Rohrbaugh MJ, Shoham V, Sonnega JS, Nicklas JM, Cranford JA. Prognostic importance of marital quality for survival of congestive heart failure. Am. J. Cardiol. 2001; 88:526-529. [PubMed: 11524062]

15. Chin MH, Goldman L. Correlates of early hospital readmission or death in patients with congestive heart failure. Am. J. Cardiol. 1997; 79:1640-1644. [PubMed: 9202355]

16. DiMatteo MR. Social support and patient adherence to medical treatment: A meta-analysis. Health Psychol. 2004; 23:207-218. [PubMed: 15008666]

17. Kulkarni SP, Alexander KP, Lytle B, Heiss G, Peterson ED. Long-term adherence with cardiovascular drug regimens. Am. Heart J. 2006; 151:185-191. [PubMed: 16368315]

18. Trivedi RB, Ayotte B, Edelman D, Bosworth HB. The association of emotional well-being and marital status with treatment adherence among patients with hypertension. J. Behav. Med. 2008; 31:489-497. [PubMed: 18780175] 
19. Zaghloul SS, Cunliffe WJ, Goodfield MJ. Objective assessment of compliance with treatments in acne. Br. J. Dermatol. 2005; 152:1015-1021. [PubMed: 15888162]

20. Wu JR, Moser DK, Chung ML, Lennie TA. Objectively measured, but not self-reported, medication adherence independently predicts event-free survival in patients with heart failure. $\mathrm{J}$. Card. Fail. 2008; 14:203-210. [PubMed: 18381183]

21. Chung ML, Lennie TA, Riegel B, Wu JR, Dekker RL, Moser DK. Marital status as an independent predictor of event-free survival of patients with heart failure. Am. J. Crit. Care. 2009; 18:562-570. [PubMed: 19880958]

22. Baron RM, Kenny DA. The moderator-mediator variable distinction in social psychological research: Conceptual, strategic, and statistical considerations. J. Pers. Soc. Psychol. 1986; 51:1173-1182. [PubMed: 3806354]

23. Bennett JA. Mediator and moderator variables in nursing research: Conceptual and statistical differences. Res. Nurs. Health. 2000; 23:415-420. [PubMed: 11052395]

24. Sherbourne CD, Hays RD. Marital status, social support, and health transitions in chronic disease patients. J. Health Soc. Behav. 1990; 31:328-343. [PubMed: 2135935]

25. Barron CR, Foxall MJ, Von Dollen K, Jones PA, Shull KA. Marital status, social support, and loneliness in visually impaired elderly people. J. Adv. Nurs. 1994; 19:272-280. [PubMed: 8188958]

26. Adewuya AO, Owoeye OA, Erinfolami AR, Coker AO, Ogun OC, Okewole AO, et al. Prevalence and correlates of poor medication adherence amongst psychiatric outpatients in southwestern nigeria. Gen. Hosp. Psychiatry. 2009; 31:167-174. [PubMed: 19269538]

27. Molloy GJ, Perkins-Porras L, Bhattacharyya MR, Strike PC, Steptoe A. Practical support predicts medication adherence and attendance at cardiac rehabilitation following acute coronary syndrome. J. Psychosom. Res. 2008; 65:581-586. [PubMed: 19027448]

28. Rich MW, Gray DB, Beckham V, Wittenberg C, Luther P. Effect of a multidisciplinary intervention on medication compliance in elderly patients with congestive heart failure. Am. J. Med. 1996; 101:270-276. [PubMed: 8873488]

29. Wu JR, Lennie TA, De Jong MJ, Frazier SK, Heo S, Chung ML, et al. Medication adherence is a mediator of the relationship between ethnicity and event-free survival in patients with heart failure. J. Card. Fail. 2010; 16:142-149. [PubMed: 20142026]

30. Wu JR, Moser DK, De Jong MJ, Rayens MK, Chung ML, Riegel B, et al. Defining an evidencebased cutpoint for medication adherence in heart failure. Am. Heart J. 2009; 157:285-291. [PubMed: 19185635]

31. Chung ML, Lennie TA, de Jong M, Wu JR, Riegel B, Moser DK. Patients differ in their ability to self-monitor adherence to a low-sodium diet versus medication. J. Card. Fail. 2008; 14:114-120. [PubMed: 18325457]

32. Cheng CW, Woo KS, Chan JC, Tomlinson B, You JH. Association between adherence to statin therapy and lipid control in hong kong chinese patients at high risk of coronary heart disease. Br. J. Clin. Pharmacol. 2004; 58:528-535. [PubMed: 15521901]

33. Dunbar-Jacob J, Bohachick P, Mortimer MK, Sereika SM, Foley SM. Medication adherence in persons with cardiovascular disease. J. Cardiovasc. Nurs. 2003; 18:209-218. [PubMed: 12837011]

34. Hope CJ, Wu J, Tu W, Young J, Murray MD. Association of medication adherence, knowledge, and skills with emergency department visits by adults 50 years or older with congestive heart failure. Am. J. Health. Syst. Pharm. 2004; 61:2043-2049. [PubMed: 15509127]

35. Kimmel SE, Chen Z, Price M, Parker CS, Metlay JP, Christie JD, et al. The influence of patient adherence on anticoagulation control with warfarin: Results from the international normalized ratio adherence and genetics (in-range) study. Arch. Intern. Med. 2007; 167:229-235. [PubMed: 17296877]

36. Wagner GJ, Ghosh-Dastidar B. Electronic monitoring: Adherence assessment or intervention? HIV clinical trials. 2002; 3:45-51. [PubMed: 11819185]

37. Mills RM Jr. Haught WH. Evaluation of heart failure patients: Objective parameters to assess functional capacity. Clin. Cardiol. 1996; 19:455-460. [PubMed: 8790948] 
38. Wu JR, Chung M, Lennie TA, Hall LA, Moser DK. Testing the psychometric properties of the medication adherence scale in patients with heart failure. Heart Lung. 2008; 37:334-343. [PubMed: 18790334]

39. Canty-Mitchell J, Zimet GD. Psychometric properties of the multidimensional scale of perceived social support in urban adolescents. Am. J. Community Psychol. 2000; 28:391-400. [PubMed: 10945123]

40. Picardi A, Mazzotti E, Gaetano P, Cattaruzza MS, Baliva G, Melchi CF, et al. Stress, social support, emotional regulation, and exacerbation of diffuse plaque psoriasis. Psychosomatics. 2005; 46:556-564. [PubMed: 16288135]

41. Derogatis LR, Melisaratos N. The brief symptom inventory: An introductory report. Psychol. Med. 1983; 13:595-605. [PubMed: 6622612]

42. Kroenke K, Spitzer RL, Williams JB. The phq-9: Validity of a brief depression severity measure. J. Gen. Intern. Med. 2001; 16:606-613. [PubMed: 11556941]

43. Ackermann RT, Rosenman MB, Downs SM, Holmes AM, Katz BP, Li J, et al. Telephonic casefinding of major depression in a medicaid chronic disease management program for diabetes and heart failure. Gen. Hosp. Psychiatry. 2005; 27:338-343. [PubMed: 16168794]

44. MacKinnon DP, Lockwood CM, Hoffman JM, West SG, Sheets V. A comparison of methods to test mediation and other intervening variable effects. Psychol Methods. 2002; 7:83-104. [PubMed: 11928892]

45. MacKinnon DP, MacKinnon DP, Dwyer JH. Estimating mediated effects in prevention studies. Eval. Rev. 1993; 17:144-158.

46. Sonnentag S, Zijlstra FR. Job characteristics and off-job activities as predictors of need for recovery, well-being, and fatigue. J. Appl. Psychol. 2006; 91:330-350. [PubMed: 16551187]

47. Krumholz HM, Butler J, Miller J, Vaccarino V, Williams CS, Mendes de Leon CF, et al. Prognostic importance of emotional support for elderly patients hospitalized with heart failure. Circulation. 1998; 97:958-964. [PubMed: 9529263]

48. Kaona FA, Tuba M, Siziya S, Sikaona L. An assessment of factors contributing to treatment adherence and knowledge of tb transmission among patients on tb treatment. BMC Public Health. 2004; 4:68. [PubMed: 15625004]

49. Nguyen GC, LaVeist TA, Harris ML, Datta LW, Bayless TM, Brant SR. Patient trust-in-physician and race are predictors of adherence to medical management in inflammatory bowel disease. Inflamm. Bowel Dis. 2009; 15:1233-1239. [PubMed: 19177509]

50. Silva MC, Ximenes RA, Filho DB Miranda, Arraes LW, Mendes M, Melo AC, et al. Risk-factors for non-adherence to antiretroviral therapy. Rev. Inst. Med. Trop. Sao Paulo. 2009; 51:135-139. [PubMed: 19551287]

51. Sayers SL, Riegel B, Pawlowski S, Coyne JC, Samaha FF. Social support and self-care of patients with heart failure. Ann. Behav. Med. 2008; 35:70-79. [PubMed: 18347906]

52. Diercks DB, Fonarow GC, Kirk JD, Emerman CL, Hollander JE, Weber JE, et al. Risk stratification in women enrolled in the acute decompensated heart failure national registry emergency module (adhere-em). Acad. Emerg. Med. 2008; 15:151-158. [PubMed: 18275445]

53. Mullens W, Abrahams Z, Sokos G, Francis GS, Starling RC, Young JB, et al. Gender differences in patients admitted with advanced decompensated heart failure. Am. J. Cardiol. 2008; 102:454 458. [PubMed: 18678305] 
Kaplan-Meier Survival Plot of Marital Status and Event-free Survival

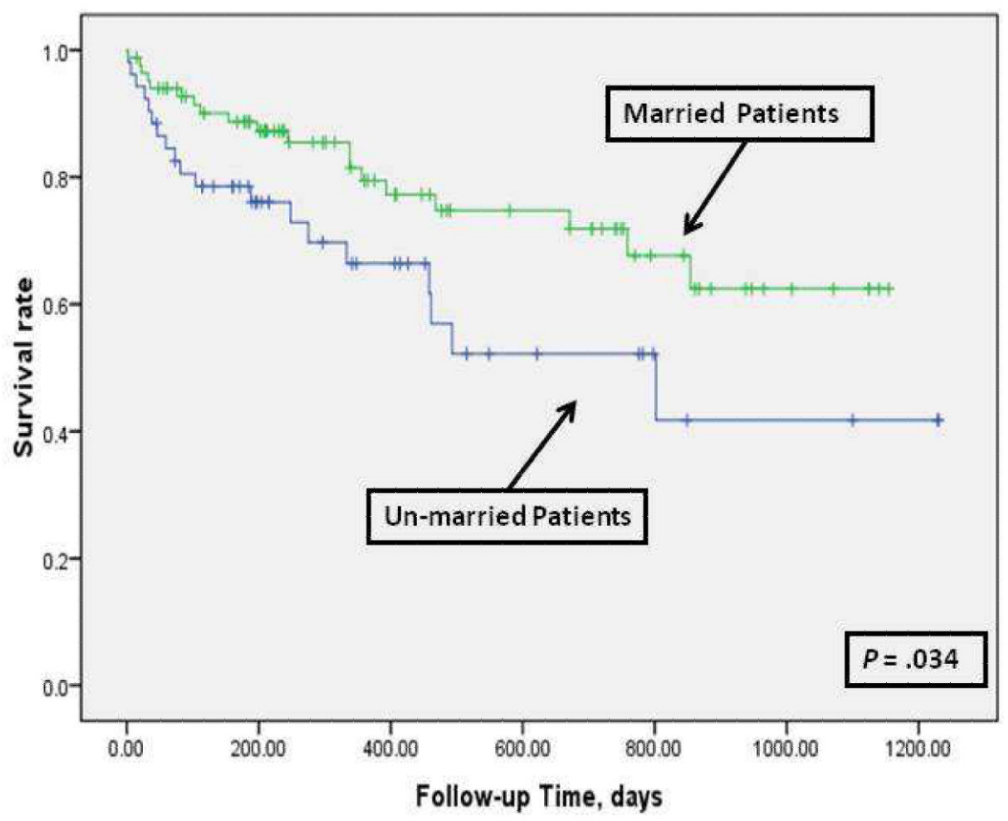

Figure 1.

Kaplan-Meier survival plot of marital status and event-free survival 


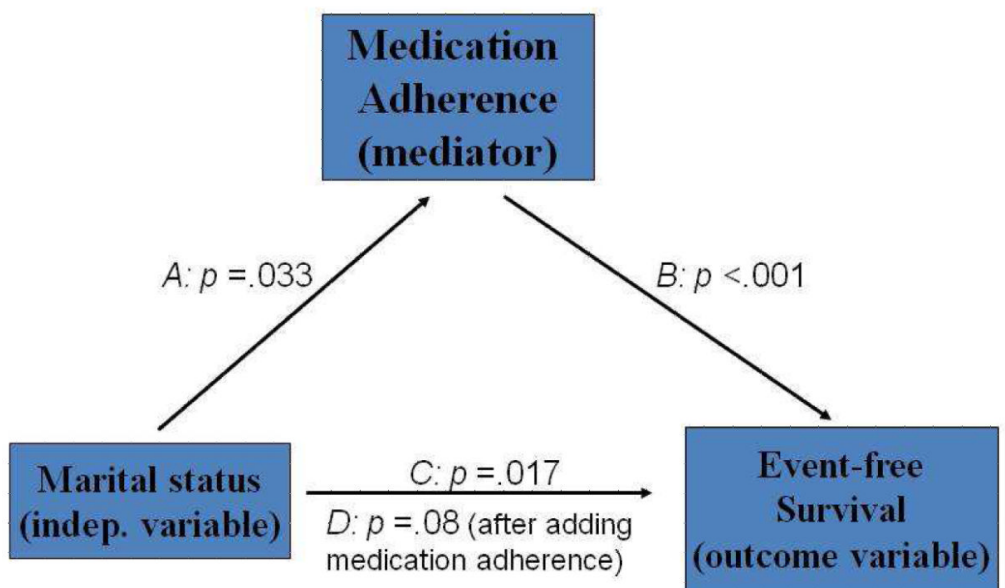

Figure 2.

Medication adherence is a mediator between marital status and event-free survival Path A: Test of whether marital status is a predictor of medication adherence.

Path B: Test of whether medication adherence is a predictor of cardiac event-free survival. Path C: Test of whether marital status is a predictor of cardiac event-free survival. Path D: Test of whether marital status and medication adherence together are predictors of cardiac event-free survival. 
Table 1

Sample Characteristics and comparison of married vs. unmarried groups

\begin{tabular}{|c|c|c|c|c|}
\hline Characteristics & $\begin{array}{l}\text { Total Sample } \\
(\mathbf{N}=136)\end{array}$ & $\begin{array}{l}\text { Married } \\
(n=84)\end{array}$ & $\begin{array}{l}\text { Unmarried } \\
(\mathbf{n}=52)\end{array}$ & $p$ \\
\hline Age, years & $61(11)$ & $60(11)$ & $62(11)$ & .32 \\
\hline Female & $41(30.1)$ & $18(21.4)$ & $23(44.2)$ & .01 \\
\hline Education & $12.6(3.3)$ & $12.4(3.5)$ & $12.8(2.8)$ & .45 \\
\hline Financial status & & & & .41 \\
\hline Comfortable & $33(24.6)$ & $23(27.7)$ & $10(19.6)$ & \\
\hline Enough to make ends meet & $71(53.0)$ & $44(53.0)$ & $27(52.9)$ & \\
\hline Not enough to make ends meet & $30(22.4)$ & $16(19.3)$ & $14(27.5)$ & \\
\hline \multicolumn{5}{|c|}{ With government or commercial insurance } \\
\hline With government insurance & $106(77.9)$ & $66(78.6)$ & $40(76.9)$ & .83 \\
\hline LVEF, \% & $34.6(14.1)$ & $33.7(13.6)$ & $36.1(15.1)$ & .34 \\
\hline NYHA functional class & & & & .19 \\
\hline $\mathrm{I} / \mathrm{II}$ & $54(39.7)$ & $34(40.4)$ & $20(38.4)$ & \\
\hline III & $63(46.3)$ & $42(50.0)$ & $21(40.4)$ & \\
\hline IV & $19(14.0)$ & $8(9.5)$ & $11(21.2)$ & \\
\hline Charlson comorbidity index & $3.3(1.7)$ & $3.3(1.7)$ & $3.5(1.6)$ & .51 \\
\hline Hypertension & $104(79.4)$ & $64(79.0)$ & $40(80.0)$ & 1.00 \\
\hline Diabetes & $64(47.8)$ & $37(45.1)$ & 27 (51.9) & .48 \\
\hline Stroke & $25(18.7)$ & $16(19.5)$ & $9(17.3)$ & .82 \\
\hline Previous MI & $80(61.1)$ & $49(61.3)$ & $31(60.8)$ & 1.0 \\
\hline BMI & $31.8(6.6)$ & $32.3(6.7)$ & $31.1(6.5)$ & .32 \\
\hline Taking BB & $121(89.0)$ & $76(90.5)$ & $45(86.5)$ & .58 \\
\hline Perceived social support & $66.3(18.4)$ & $70.8(15.1)$ & $58.8(21.0)$ & .01 \\
\hline Anxiety & $.73(.75)$ & $.74(.69)$ & $.72(.86)$ & .89 \\
\hline Depressive symptoms & $7.0(.59)$ & $6.7(5.7)$ & $7.3(6.2)$ & .61 \\
\hline Medication adherence & $80.7(22.8)$ & $85.1(18.2)$ & $73.7(27.4)$ & .01 \\
\hline
\end{tabular}

Data are presented as means (SD), or N (\%), interval level data compared by independent t-test, nominal and categorical by Chi-square; $\mathrm{BB}=$ beta blocker; $\mathrm{LVEF}=$ left ventricular ejection fraction; $\mathrm{MI}=$ myocardial infarction; NYHA = New York Heart Association 
Table 2

Cox Regression Modeling: Marital Status on Cardiac Event-free Survival ( $\mathrm{N}=136)$

\begin{tabular}{lccc}
\hline Variables & Hazard Ratio & 95\% CI & $p$ \\
\hline Simple Cox Regression & & & \\
Marital status & 2.13 & $1.15-3.94$ & .017 \\
\hline Multiple Cox Regression & & & \\
Step1 & & & \\
Age & .98 & $.95-1.02$ & .349 \\
Gender & .70 & $.30-1.63$ & .405 \\
Education level & 1.00 & $.85-1.17$ & .965 \\
LVEF & .99 & $.96-1.02$ & .508 \\
NYHA & 1.19 & $.77-1.84$ & .441 \\
BMI & .93 & $.87-.99$ & .021 \\
Perceived social support & 1.00 & $.98-1.02$ & .793 \\
Anxiety & 1.15 & $.75-1.77$ & .529 \\
Depressive symptoms & 2.31 & $1.01-5.31$ & .048 \\
\hline Step2 & & $1.02-4.07$ & .044 \\
Marital status & & & \\
\hline Step3 & 2.04 & .001 \\
\hline Medication adherence & & & \\
\hline & & & \\
\hline
\end{tabular}

BMI = Body Mass Index $; \mathrm{CI}=$ confidence interval; $\mathrm{LVEF}=$ left ventricular ejection fraction; NYHA = New York Heart Association 